\title{
Abdominal Cutaneous Nerve Entrapment Syndrome, Case Report and Diagnostic Evaluation
}

\section{Síndrome de compressão do nervo cutâneo abdominal, relato de caso e avaliação diagnóstica}

\author{
Jose Fernando Guedes-Correa ${ }^{1}$ Stephanie Oliveira Fernandes de Bulhões ${ }^{10}$ \\ ${ }^{1}$ Division of Neurosurgery, Hospital Universitário Gaffrée e Guinle, Rio \\ de Janeiro, RJ, Brazil \\ Arq Bras Neurocir 2019;38:141-144. \\ Address for correspondence Stephanie Oliveira Fernandes de \\ Bulhões, Research Internship, Division of Neurosurgery, Hospital \\ Universitário Gaffrée e Guinle, Rio de Janeiro, Rio de Janeiro, Brazil \\ (e-mail: stephanie_bulhoes@hotmail.com).
}

\section{Abstract \\ Keywords \\ - nerve compression syndrome \\ - ultrasonography \\ - diagnostic imaging}

\section{Resumo}

Palavras-chave

- síndromes de compressão nervosa

- ultrassonografia

- diagnóstico por imagem
Abdominal cutaneous nerve entrapment is a rarely diagnosed condition that leads to intense neuropathic pain in the anterolateral wall of the abdomen. Generally, it is triggered by some factor implied in the increase of the pressure on the nerve in its passage by the abdominal wall. Its most important differential diagnosis is pain of visceral origin.

We present a case in which the clinical findings confirmed on ultrasound and other imaging tests established the diagnosis and in which the noninvasive treatment was effective.

A compressão do nervo cutâneo abdominal é uma condição raramente diagnosticada que causa dor neuropática intensa na parede anterolateral do abdome. Geralmente, ela é iniciada por algum fator implicado no aumento da pressão sobre o nervo na passagem deste pela parede abdominal. Seu diagnóstico diferencial mais importante é a dor de origem visceral.

Apresentamos um caso no qual os achados clínicos confirmados por ultrassonografia e por outros exames de imagem firmaram o diagnóstico e no qual o tratamento não invasivo foi efetivo.

\section{Introduction}

Abdominal cutaneous nerve entrapment syndrome (ACNES) is a commonly misdiagnosed condition, its prevalence among patients referred to general practitioners, abdominal surgeons, or pain clinics for chronic abdominal pain ranges from 10 to $30 \%^{1,2}$ In an emergency department setting studied by van Assen et $\mathrm{al}^{3}{ }^{3}$ it was found that $\sim 2 \%$ of the patients with acute abdominal pain had ACNES. The most

(1) Stephanie Oliveira Fernandes de Bulhõe's ORCID is 0000-0002-31688384.

received

November 26, 2018

accepted

February 19, 2019
DOI https://doi.org/

10.1055/s-0039-1685149. ISSN 0103-5355. common symptom is a dull or burning pain with a sharp, well-localized component in a restricted area of the abdominal wall. The pain can be chronic or acute. It generally arises from lower intercostal nerves (T8-T11) probably caused by entrapment of the cutaneous abdominal nerve at the lateral border of the rectus abdominis muscle (RAM), specifically where this nerve enters the RAM channel through a fibrous ring. As the nerve passes through the RAM, each nerve and its vessels are surrounded by fat, binding the nerve, arteries and veins into a bundle. Separating the bundle from the muscle, there is the fibrous ring situated about midway between the anterior surface of the

Copyright $\odot 2019$ by Thieme Revinter Publicações Ltda, Rio de Janeiro, Brazil 
RAM and its posterior side, providing a smooth environment through which the bundle can slide. This area is believed to be more susceptible to ischemia or to physical compression of the nerve due to the juxtaposition of the soft neurovascular bundle to the firm fibrous ring. ${ }^{2-10}$

We present a case of ACNES seen at the Division of Neurosurgery of the Hospital Universitário Gaffrée e Guinle of the Universidade Federal do Estado do Rio de Janeiro (HUGG - UNIRIO, in the Portuguese acronym), calling attention to the clinical diagnosis, pointing out its imaging characteristics, highlighting the value of high definition linear ultrasound (HDLUS) as a valuable diagnostic method and showing that a noninvasive treatment can be effective.

\section{Case Report}

A Caucasian male, 69 years old, presented with burning pain on the right anterolateral abdominal wall in the region of the T9-T10 dermatomes. The pain had begun 4 months earlier and started after lifting a heavy weight. The patient had diabetes mellitus (DM), systemic arterial hypertension, and was overweight $\left(29.1 \mathrm{~kg} / \mathrm{m}^{2}\right)$.

A general practitioner, a cardiologist, and a general surgeon successively evaluated the patient. The cardiological tests, the thoracic abdominal and pelvic computed tomography (CT), and the abdominal-pelvic magnetic resonance imaging (MRI) that were requested for investigation were all considered inconclusive.

The patient was seen at the HUGG neurosurgery division due to the persistence of pain with neuropathic characteristics. At the neurological evaluation, he reported intense burning pain at the left T9-T10 dermatome area (visual analogue scale [VAS] 8), with no changes at ectoscopy apart from the overweight. The pain was continuous without remission periods and extremely worse during the night. The patient presented with hypoesthesia and discriminative sensibility was reduced compared with the contralateral abdominal wall in the T9-T10 area. The Carnett test was positive. The Valsalva maneuver also enhanced the pain.

As the previous imaging exams of the patient were inconclusive and intercostal nerve compromise was sus- pected, it was performed a HDLUS of the abdominal wall that demonstrated the left RAM and its sheath lesion in a paramedian and supraumbilical topography with cicatricial fibroadipose tissue. The muscle injury was associated with fibrocicatricial thickening of the abdominal cutaneous nerve. Supraumbilical diastasis of the RAM could also be noticed. (-Fig. 1)

Other imaging studies (MRI and CT) were reanalyzed by the radiologist of our institution, after the diagnosis with HDLUS. Some abnormalities were noticed with the reevaluation of the images, such as high signal intensity on the MRI $\mathrm{T} 2$ image and decreased density on the $\mathrm{CT}$ image around the RAM strain area. (-Fig. 2)

With a clinical and imaging diagnosis of ACNES, the patient was oriented to nutritional evaluation for weight control and pregabalin was administered at a dose of $75 \mathrm{mg} 3$ times a day in the $1^{\text {st }}$ month. The patient was accompanied at the outpatient clinic and, after 2 months, reported pain relief of $80 \%$ (VAS dropped from 8 to 3 ). Three months after the beginning of the treatment, the patient reported a total relief of pain and, after 10 months, he had lost $15 \mathrm{~kg}$ and the pregabalin administration could be reduced to $75 \mathrm{mg} /$ day. The last evaluation was 1 year after the diagnosis, the patient was on physiotherapy, had a normal control of his DM and continued nutrition support. The pain did not return.

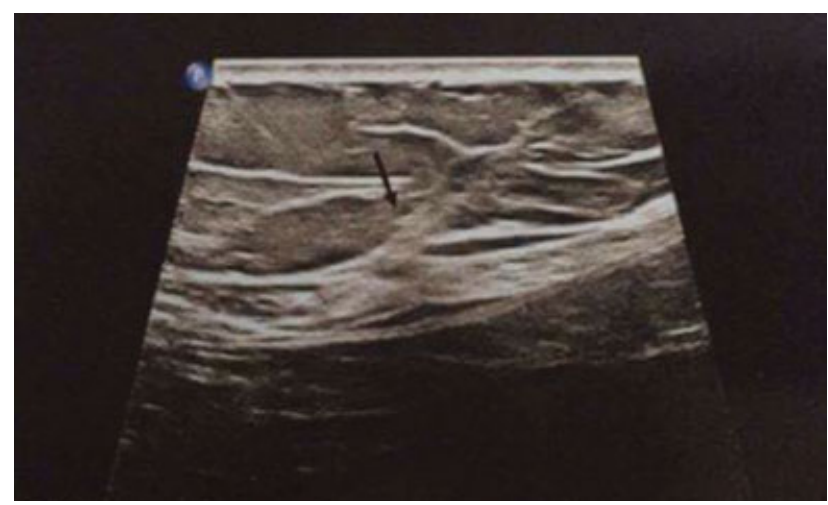

Fig. 1 Ultrasound of abdomen; arrow shows fibrocicatricial thickening of the abdominal cutaneous nerve (black arrow).

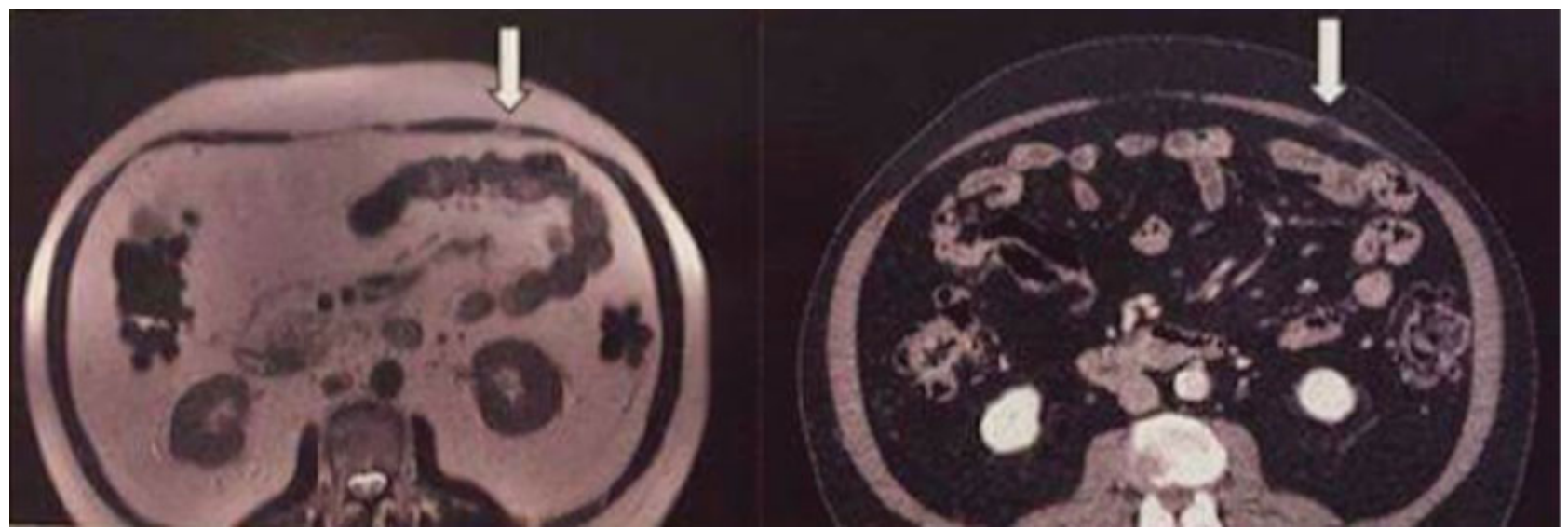

Fig. 2 On the right axial abdominal MRI (T2) and on the left axial abdominal CT; both demonstrate the rectus abdominis strain area (white arrow). 


\section{Discussion}

Abdominal cutaneous nerve entrapment syndrome is a commonly misdiagnosed condition that can have visceral pain as differential diagnosis, or the patient might even present with a coexisting visceral condition that does not explain the pain by itself. Therefore, it is important to recognize the clinical signs of ACNES and to look for the imaging characteristics of the lesion. . $^{3-5,9-15}$

Typically a unilateral neuropathic pain in the area of the T8T11 dermatomes with hypoesthesia in this same region, ACNES has an important clinical test, formulated by Carnett, ${ }^{16}$ to aid in the diagnosis. This test is based on the presumption that if the pain has a visceral origin, the tensed abdominal muscles guard the underlying structures, reducing tenderness, whereas continued tenderness during muscle contraction implicates the abdominal wall as the source of the pain. In the presented case, the Carnett test was positive and the Valsalva maneuver enhanced the pain, as it can increase the abdominal pressure to the entrapped nerve. ${ }^{2-6,11,16,17}$

The next diagnostic step would be the imaging evaluation. Conventionally, to study the abdomen, physicians can use CT, MRI, and ultrasound (US). Computed tomography is the most commonly used in the emergency room in patients whose first clinical hypothesis is a visceral pain, and that was the case of our patient, who also underwent an MRI because of this suspicion. However, although the images showed indeed high signal intensity on MRI T2 and a decreased density on CT at the RAM strain area (-Fig. 2), probably indicating fibrocicatricial tissue, as ACNES was not a clinical suspicion at the moment, these abnormities were only seen after the reevaluation of the imaging exams in our institution. ${ }^{12-14,18}$

Nonetheless, although we could presume that the best imaging exam for these cases would be MRI, given that the abnormities can be seen if followed by the clinical suspicion, and that this exam is known to be one of the best to study muscles, we should not forget that it is also one of the most expensive. ${ }^{18}$ Therefore, neuromuscular HDLUS (18-5 MHz), used in the present case, is a great contribution in the hands of an experienced examiner, revealing itself even more sensitive to diagnose some neuromuscular lesions than MRI, despite being an examiner-dependent technique. In addition, it is a relatively cheap and fast exam. ${ }^{19}$

Although Kanakarajan et al have already discussed the importance of US on ACNES as a guidance to therapeutic injections, we suggest its use for diagnostic purposes. ${ }^{8}$

With the use of HDLUS on the abdominal wall, it is possible to differentiate fiber discontinuity due to muscle strain of the RAM as decreased echogenicity areas and the fibrocicatricial tissue can be localized as increased echogenicity areas, corroborating the abnormalities found on the MRI and CT exams, imaging methods that demand more time and are more expensive. ${ }^{18}$ So, if the clinical evaluation indicates that that problem is on the abdominal wall and not from a visceral origin, we suggest the use of HDLUS as the first imaging modality exam.

Nowadays, it is recognized that a multimodal approach for such cases is paramount, especially in chronic refractory cases. However, some authorities ${ }^{14,15,20}$ try to confirm the diagnosis and use trigger point injection (lidocaine) without mentioning any systemic drug (nonsteroidal anti-inflammatory drugs, weak opioids, antiepileptics, and antidepressants) or other multimodal treatment. ${ }^{4}$

Weight control, physiotherapy, and systemic drug administration following the guidelines for neuropathic pain therapy was the protocol established for the presented case. The result was positive with this noninvasive management. It is important to point out, as the current literature reports, that systemic drugs may be used as a first step or as a complementary treatment for ACNES, considering the result with chronic pain relief. However, these studies do not confirm if the administration of systemic drugs alone can help patients with ACNES. ${ }^{4}$

If the use of systemic drugs fails to decrease the pain, the best option would be lidocaine trigger point injection, preferably ultrasound-guided, not associated with corticosteroids, as this combination is not certain to increase the success of this therapy. As for refractory cases in which multiple trigger point injections associated with a multimodal approach does not have success, the patient might need a more invasive strategy, such as a neurectomy of the anterior cutaneous nerve endings. These two types of management can lead to long-term pain relief in $\sim 75 \%$ of the patients with ACNES. 4,14,15,20

Other options described in the literature would be pulsed radio frequency treatment, spinal cord stimulation of the dorsal root ganglion, and intraperitoneal onlay mesh reinforcement. However, these methods still need further studies to confirm their efficacy. $4,21,22$

An important bias of our study is the fact that HDLUS, used in the presented case, is an examiner-dependent method, and that we compare only one case to the current English published literature, which may lead to some disagreements that could be overcome on a larger sample.

\section{Conclusion}

Patients who present on clinical evaluation with unilateral neuropathic pain in the area of the T8-T11 dermatomes, hypoesthesia in this same region should be investigated for ACNES with HDLUS performed by an experienced professional reducing the costs to conclude a correct diagnose, and the noninvasive management might be helpful and effective.

Note

We declare that the present manuscript has not been previously published in whole or in part or submitted elsewhere for review and we report no conflicts of interest concerning the materials or methods used in the present study or the findings specified in the present paper.

Conflicts of Interests

The authors have no conflicts of interests to declare.

\section{References}

1 McGarrity TJ, Peters DJ, Thompson C, McGarrity SJ. Outcome of patients with chronic abdominal pain referred to chronic pain clinic. Am J Gastroenterol 2000;95(07):1812-1816 
2 Lindsetmo RO, Stulberg J. Chronic abdominal wall pain-a diagnostic challenge for the surgeon. Am J Surg 2009;198(01): 129-134. Doi: 10.1016/j.amjsurg.2008.10.027

3 van Assen T, Brouns JA, Scheltinga MR, Roumen RM. Incidence of abdominal pain due to the anterior cutaneous nerve entrapment syndrome in an emergency department. Scand J Trauma Resusc Emerg Med 2015;23:19-24

4 Chrona E, Kostopanagiotou G, Damigos D, Batistaki C. Anterior cutaneous nerve entrapment syndrome: management challenges. J Pain Res 2017;10:145-156. Doi: 10.2147/JPR.S99337

5 Koop H, Koprdova S, Schürmann C. Chronic Abdominal Wall Pain. Dtsch Arztebl Int 2016;113(04):51-57. Doi: 10.3238/arztebl.2016.0051

6 Applegate WV. Abdominal cutaneous nerve entrapment syndrome (ACNES): a commonly overlooked cause of abdominal pain. Perm J 2002;6:20-27

7 Siawash M, de Jager-Kievit JW, Ten WT, Roumen RM, Scheltinga MR. Prevalence of anterior cutaneous nerve entrapment syndrome in a pedi- atric population with chronic abdominal pain. J Pediatr Gastroenterol Nutr 2016;62(03):399-402

8 Kanakarajan S, High K, Nagaraja R. Chronic abdominal wall pain and ultrasound-guided abdominal cutaneous nerve infiltration: a case series. Pain Med 2011;12(03):382-386

9 Siawash M, Maatman R, Tjon A Ten W, van Heurn E, Roumen R, Scheltinga M. Anterior neurectomy in children with a recalcitrant anterior cutaneous nerve entrapment syndrome is safe and successful. J Pediatr Surg 2017;52(03):478-480

10 Applegate WV, Buckwalter NR. Microanatomy of the structures contributing to abdominal cutaneous nerve entrapment syndrome. J Am Board Fam Pract 1997;10(05):329-332

11 Srinivasan R, Greenbaum DS. Chronic abdominal wall pain: a frequently overlooked problem. Practical approach to diagnosis and management. Am J Gastroenterol 2002;97(04):824-830

12 van Assen T, de Jager-Kievit JW, Scheltinga MR, Roumen RM. Chronic abdominal wall pain misdiagnosed as functional abdominal pain. J Am Board Fam Med 2013;26(06):738-744
13 Imajo Y, Komasawa N, Fujiwara S, Minami T. Transversus abdominal plane and rectus sheath block combination for intractable anterior cutaneous nerve entrapment syndrome after severe cholecystitis. J Clin Anesth 2016;31:119

14 Boelens OB, Scheltinga MR, Houterman S, Roumen RM. Randomized clinical trial of trigger point infiltration with lidocaine to diagnose anterior cutaneous nerve entrapment syndrome. $\mathrm{Br} \mathrm{J}$ Surg 2013;100(02):217-221

15 Boelens OB, Scheltinga MR, Houterman S, Roumen RM. Management of anterior cutaneous nerve entrapment syndrome in a cohort of 139 patients. Ann Surg 2011;254(06): 1054-1058

16 Carnett JB. Intercostal neuralgia as a cause of abdominal pain and tenderness. Surg Gynecol Obstet 1926;42:625-632

17 Sharpstone D, Colin-Jones DG. Chronic, non-visceral abdominal pain. Gut 1994;35(06):833-836

18 Campbell SE, Adler R, Sofka CM. Ultrasound of muscle abnormalities. Ultrasound Q 2005;21(02):87-94, quiz 150, 153-154

19 Zaidman CM, Seelig MJ, Baker JC, Mackinnon SE, Pestronk A. Detection of peripheral nerve pathology: comparison of ultrasound and MRI. Neurology 2013;80(18):1634-1640

20 Mol FMU, Jansen $\mathrm{CH}$, Boelens $\mathrm{OB}$, et al. Adding steroids to lidocaine in a therapeutic injection regimen for patients with abdominal pain due to anterior cutaneous nerve entrapment syndrome (ACNES): a single blinded randomized clinical trial. Scand J Pain 2018;18(03):505-512

21 Téllez Villajos L, Hinojal Olmedillo B, Moreira Vicente V, de la Calle Reviriego JL, Senosiain Lalastra C, Foruny Olcina JR. [Pulsed radiofrequency in the treatment of abdominal cutaneous nerve entrapament syndrome]. Gastroenterol Hepatol 2015;38(01): 14-16

22 Mol FMU, Roumen RMH. DRG Spinal Cord Stimulation as Solution for Patients With Severe Pain Due to Anterior Cutaneous Nerve Entrapment Syndrome: A Case Series. Neuromodulation 2018;21 (03):317-319 